\title{
Lymphangioleiomyomatosis: what do we know and what are we looking for?
}

\author{
S. Harari*, O. Torre* and J. Moss ${ }^{\#}$
}

ABSTRACT: Lymphangioleiomyomatosis (LAM) is a rare disease characterised by proliferation of abnormal smooth muscle-like cells (LAM cells) leading to progressive cystic destruction of the lung, lymphatic abnormalities and abdominal tumours. It affects predominantly females and can occur sporadically or in patients with tuberous sclerosis complex.

This review describes the recent progress in our understanding of the molecular pathogenesis of the disease and LAM cell biology. It also summarises current therapeutic approaches and the most promising areas of research for future therapeutic strategies.

\section{KEYWORDS: LAM cells, lymphangioleiomyomatosis, tuberous sclerosis complex}

ymphangioleiomyomatosis (LAM) is a rare multisystem disorder affecting predominantly young females in their reproductive years. It is characterised by progressive cystic destruction of the lung, lymphatic abnormalities and abdominal tumours (e.g. angiomyolipomas) [1-5]. The main feature of the disease is the proliferation of abnormal smooth muscle-like cells (LAM cells), leading to the formation of thin-walled cysts in the lungs and cystic structures (i.e. lymphangioleiomyoma) in the axial lymphatics. LAM is also characterised by high prevalence of angiomyolipomas (AMLs), benign tumours which involve primarily the kidneys, composed of smooth muscle cells and adipocytes together with incomplete blood vessels [1-5].

LAM arise sporadically in otherwise healthy females and in about $30 \%$ of females with tuberous sclerosis complex (TSC), an autosomal dominant syndrome characterised by hamartoma formation in multiple organ systems, cerebral calcifications, seizures and cognitive defects [6-9]. In the past decades, the finding that LAM lesions in patients with TSC (TSC-LAM) and sporadic LAM (S-LAM) are histologically identical was consistent with the hypothesis that these diseases may share common genetic and pathogenetic mechanisms. In this review, we will focus on current concepts of the molecular pathogenesis of LAM and the rationale of currently available and experimental treatment.

\section{PATHOGENESIS}

Pathology of LAM lesions and characterisation of LAM cells

Lung lesions in LAM are characterised by lung nodules or small cell clusters of LAM cells near cystic lesions and along pulmonary bronchioles, blood vessels and lymphatics (figs 1 and 2). LAM cells consist of two types of cell subpopulations: myofibroblast-like spindle-shaped cells expressing smooth muscle-specific proteins, such as $\alpha$-actin, desmin and vimentin, and epithelioid-like cells, which express glycoprotein gp100, a marker of melanoma cells and immature melanocytes showing immunoreactivity with human melanoma black 45 (HMB45) monoclonal antibody [10-12]. Although the significance of gp100 expression by LAM cells is still uncertain, it appears to correlate inversely with the expression of proliferating cell nuclear antigen (PCNA), a marker of DNA synthesis and cell proliferation [13]: the spindleshaped cells forming the core of the nodules show low gp100 expression and high PCNA expression while epithelioid cells in the periphery of the nodule exhibit the reverse pattern. Thus, the spindleshaped cells may represent the proliferative element of LAM lesions [14].

LAM cells also express oestrogen and progesterone receptors and LAM may worsen during pregnancy $[10,11]$, suggesting that cell proliferation may be modulated by hormonal factors [15-17]. The HMB45-positive LAM cell phenotype also includes the muscular elements of AMLs [18] where they are combined with dysplastic blood vessels and adipocytes $[19,20]$. In the axial lymphatics, LAM cells form chaotic clumps of cells, leading to thickening of lymphatic walls, obliteration of the vessel lumen and cystic dilatation.

Although the origin of LAM cells remains unclear, recent data indicate that they can metastasize, suggesting similarities between migrating LAM
AFFILIATIONS

*Unità Operativa di Pneumologia e Terapia Semi-Intensiva Respiratoria Servizio di Fisiopatologia Respiratoria ed Emodinamica Polmonare

Ospedale San Giuseppe, Milan, Italy. \#Translational Medicine Branch, National Heart, Lung and Blood Institute, National Institutes of Health, Bethesda, MD, USA.

CORRESPONDENCE

S. Harari

Unità di Pneumologia e Terapia Semi-Intensiva Respiratoria

Ospedale San Giuseppe

via San Vittore 12

20123 Milan

Italy

E-mail: sharari@ilpolmone.it

Received:

Dec 082010

Accepted after revision:

Jan 132011

PROVENANCE

Submitted article, peer reviewed.

European Respiratory Review

Print ISSN 0905-9180

Online ISSN 1600-0617 


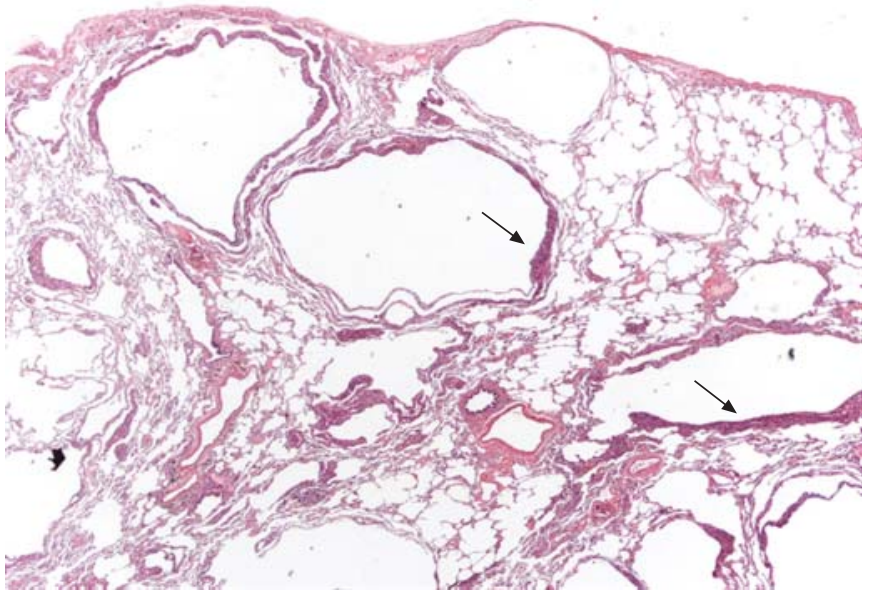

FIGURE 1. Surgical lung biopsy showing several thin-walled rounded cysts of varying dimensions. The LAM cells form small plaques in the wall of the cysts (arrows) (haematoxylin-eosin, $20 \times$ ). Figure courtesy of A. Cavazza.

cells and either mesenchymal stem cells $[13,14]$ or migrating cancer stem cells [21]. Indeed, LAM cells have been found in the blood, chylous fluids, and urine of some LAM patients [22], demonstrating that LAM cells can leave primary lesions and disseminate through blood or lymph vessels. A LAM cell lesion of recipient origin was detected after single-lung transplantation in a patient with LAM [23]. Identical TSC2 gene mutations in pulmonary LAM cells and AMLs of TSC patients with LAM have also been reported [24]. Lesions with identical mutations of the tumour suppressor TSC2 gene in the lymph nodes of patients with LAM were also found [23, 25].

\section{Genetic and molecular pathogenesis}

Mutations in the tuberous sclerosis genes TSC1 and TSC2 are considered to be the cause of LAM, with TSC2 mutations arising more frequently than TSC1 mutations (the majority of LAM, and $\sim 60 \%$ of TSC cases) [21, 26, 27]. The current accepted model for LAM is consistent with Knudson's "twohit" hypothesis of tumour development [28]: an initial mutation in either TSC1 or TSC2 is followed by a second hit represented by loss of heterozygosity, causing the loss of function of either TSC1 or TSC2 gene products. S-LAM develops due to two acquired mutations (usually in TSC2), while patients with TSC-LAM have one germline mutation (again usually in TSC2) and one acquired mutation [10]. These findings clarify why LAM is frequent in patients with TSC, while S-LAM is a particularly rare disease.

The protein products of TSC1 and TSC2, whose names are derived from characteristic phenotypic features of patients with TSC, are hamartin and tuberin, respectively [29, 30]. Hamartin is a $130-\mathrm{kDa}$ protein containing a potential transmembrane domain near its N-terminus, a coiled-coil domain, an interaction site with tuberin and ezrin-radixin-moesin (ERM) family-binding domain [31, 32]. Its C-terminal domain binds to neurofilament L (NF-L) in cortical neurons [33].

Tuberin is a $198-\mathrm{kDa}$ protein that interacts with hamartin through its N-terminus [31,34]. Tuberin also has a region of

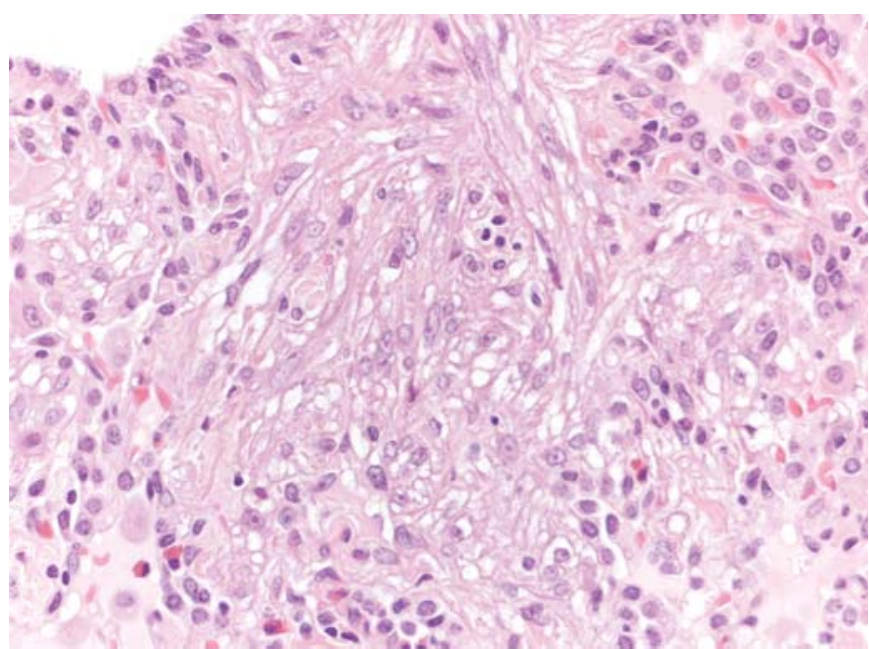

FIGURE 2. Surgical lung biopsy showing LAM cells. Note the spindle-toepithelioid morphology, the large amount of eosinophilic cytoplasm and the bland nuclei (haematoxylin-eosin, $200 \times$ ). Figure courtesy of A. Cavazza.

homology with the Rap 1 GTPase-activating protein (Rap1GAP) $[30,35]$. Finally, tuberin contains multiple potential phosphorylation sites for different kinases such as protein kinase B (Akt/ PKB) [30, 35-40]. The many and varied domains in hamartin and tuberin reflect the important role for the two proteins in the transduction of signals from cell membrane-associated receptors. Tuberin is involved in the cell cycle and in cell growth and proliferation [41]. Hamartin is thought to have a role in the reorganisation of the actin cytoskeleton by inducing an increase in the levels of Rho-GTP and by binding activated ERM proteins [42]. Thus, absence of hamartin causes loss of focal adhesions and detachment from substrate.

Many studies demonstrated that hamartin and tuberin are closely associated in vivo [43-46]. A major role of the hamartintuberin complex is the inhibition of a kinase known as the mammalian target of rapamycin (mTOR), a central regulator of cell growth [47]. mTOR realises its effects through two main mechanisms. First, it stimulates the phosphorylation and activation of S6K, leading to ribosomal assembly. Secondly, mTOR enhances phosphorylation of 4E-BP1, a protein that binds and activates the eukaryotic translation initiation factor eIF4E, permitting protein synthesis to begin [48]. Hamartintuberin complex maintains $\mathrm{mTOR}$ in a deactivated state through tuberin's ability to stimulate GTP hydrolysis by Ras homologue expressed in brain (Rheb) [49-52]. Indeed, mutations in both hamartin and tuberin have been shown to enhance Rheb activity $[53,54]$.

Several kinases can inactivate the hamartin-tuberin complex, thus increasing mTOR activity and cell growth. Among these is $\mathrm{Akt} / \mathrm{PKB}$, a cytosolic kinase recruited to the membrane upon ligation of membrane receptor tyrosine kinases, such as the insulin receptor. Akt/PKB phosphorylates tuberin, thereby promoting dissociation of the hamartin-tuberin complex (fig. 3) $[55,56]$. However, tuberin can also be phosphorylated by extracellular signal-regulated kinase 2 (ERK2) and mitogenactivated protein kinase (MAPK)-activated protein kinase 2, resulting in inactivation of hamartin-tuberin complex $[57,58]$. 


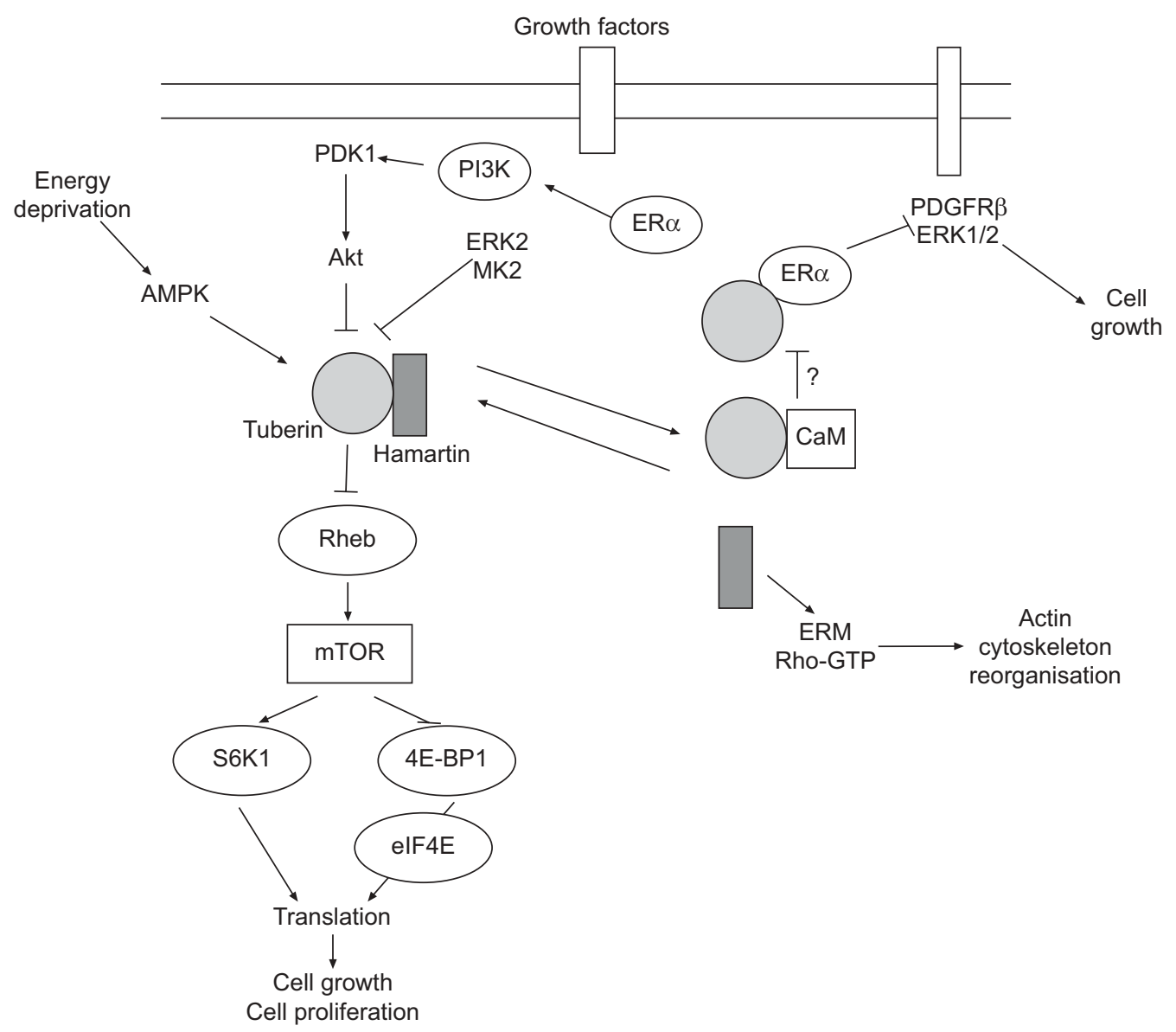

FIGURE 3. Schematic representation of the signalling transduction pathways involving the tuberous sclerosis proteins, hamartin and tuberin. The main pathway involved in lymphangioleiomyomatosis pathogenesis is mediated by Akt, whose activation inhibits hamartin-tuberin complex, leading to mammalian target of rapamycin (mTOR) activation and thus to cell growth and proliferation. Arrows indicate activating or facilitating influences; flat-headed lines indicate inhibitory influences. ERK2: extracellular signal-regulated kinase 2; MK2: mitogen-activated protein kinase (MAPK)-activated protein kinase 2; Rheb: Ras homologue expressed in brain; ER $\alpha$ : oestrogen receptor $\alpha$; PDGFR $\beta$ : platelet-derived growth factor receptor $\beta$; CaM: calmodulin; ERM: ezrin-radixin-moesin.

In contrast, under conditions of energy deprivation, an AMPactivated protein kinase (AMP kinase) phosphorylates tuberin on a site that leads to increased activity of the hamartintuberin complex and consequent inactivation of mTOR [59].

Although its role remains uncertain, oestrogen may be involved in pathogenesis of LAM by interaction with signalling events in LAM cells. Tuberin has been found to interact directly with the intracellular oestrogen receptor alpha $(E R \alpha)$ through a C-terminal domain, resulting in growth inhibition due to a reduction in oestrogen-induced activation of a platelet-derived growth factor receptor $\beta$ and extracellular signal-regulated kinase 1/2 (ERK1/2) signalling pathway [60]. Moreover, there are different nongenomic oestrogen-activated signalling pathways dependent on $\mathrm{ER} \alpha$, which may be involved in the pathogenesis of LAM. Among these, the phosphoinositide 3-kinase (PI3K)-Akt signalling cascade [61] and a pathway leading to tuberin degradation induced by dephosphorylation have been recognised [62]. Recently, the binding between calmodulin and tuberin has been hypothesised to have a role in tuberin's effects on oestrogens-mediated signalling $[63,64]$, and oestrogens have been shown to enhance survival of LAM-like cells and metastasis to the lung [65].
Altered metabolism of extracellular matrix can be involved in pathogenesis of LAM contributing to cell migration and dissemination in a manner similar to protease-mediated invasion of malignant tumours [66]. Spindle-shaped LAM cells express membrane type 1 matrix metalloproteinase (MT1 MMP) and matrix metalloproteinase 2 (MMP-2), which is activated by MT1 MMP $[67,68]$. These proteinases degrade extracellular matrix proteins thus facilitating cell migration. The observation that cleavage of insulin-like growth factor (IGF)-binding proteins by MMP-1 can promote human airway smooth muscle growth [69] suggested the hypothesis that MMPs may also enhance LAM cell growth via inactivation of IGF-binding proteins [14]. Recently, strong expression of cathepsin- $\mathrm{K}$, a protease produced normally by human osteoclasts, has been demonstrated in spindle- and epithelioid-shaped cells of LAM [70]. Cathepsin-K is a papainlike cysteine protease [71], with high matrix (collagen, elastin)degrading activity which may significantly contribute, together with metalloproteinases to the progressive structural damage and remodelling of pulmonary parenchyma [72]. Moreover, the finding of cathepsin- $\mathrm{K}$ immunoexpression in the spindle- and epithelioid smooth muscle and adipocyte-like cells in renal AMLs confirms the phenotypic identity of these morphologically 
heterogeneous cells and their relationship with the cellular elements composing the pulmonary LAM.

\section{Origins of LAM lesions}

LAM cells proliferate along lymphatics where they are divided into fascicles or bundles by channels lined by lymphatic endothelial cells. LAM cells have been hypothesised to be involved in lymphangiogenesis by producing vascular endothelial growth factor (VEGF)-C [73]. The recruitment of lymphatic channels by LAM cells may account for their ability to metastasise to distant sites and facilitate further invasion of lung tissue [74]. Obstruction and damage of lymphatics may be the mechanism involved in development of chyloptysis and chylothorax. Besides, proliferation of LAM cells along lymphatic channels puts them in proximity to both airways and blood vessels. Obstruction of blood vessels causes focal areas of haemorrhage while the cystic changes in the pulmonary parenchyma might be the result of the constrictive effect of bundles of LAM cells on airways, leading to airflow obstruction and air trapping $[75,76]$. The degradation of the supporting architecture of the pulmonary interstitium due to MMPs and cathepsin-K produced by LAM cells is considered an alternative or coexisting mechanism for cyst development (fig. 4) [68-70]. Cathepsin-K overproduction and/or the disregulation of mTOR pathway in osteoclasts may be an alternative mechanism for bone loss that has been observed in patients with LAM [70], although oestrogen deficiency has been hypothesised to be a possible cause for the abnormal bone mineral density in these patients [77].

\section{CLINICAL MANIFESTATIONS}

Pneumothorax, progressive dyspnoea and chylous pleural effusions are the main clinical manifestations of LAM [1-4, 78]. Dyspnoea is the most common symptom (over $70 \%$ of patients) and the result of airflow obstruction and cystic destruction of the lung parenchyma. Over $50 \%$ of patients have a history of pneumothorax in their clinical course. Pneumothorax is often the first manifestation and recurrences are common [4]. Chylous pleural effusions are less common, but tend to recur after simple aspiration [4, 79]. Other respiratory symptoms are cough, chyloptysis and haemoptysis (table 1). As described above, haemoptysis and chyloptysis may be the result of LAM cell obstruction of pulmonary blood vessels and lymphatics, respectively. Extrapulmonary manifestations of LAM are AMLs, which occur mostly in the kidneys, chylous ascites, abdominal lymphadenopathy and large cystic lymphatic masses termed lymphangioleiomyomas [80, 81]. AMLs are benign tumours that occur in $\sim 80 \%$ of patients with TSC-LAM and in $\sim 40 \%$ of those with S-LAM [5]. These tumours may vary in size from $1 \mathrm{~mm}$ to more than $20 \mathrm{~cm}$ in diameter, leading to complete disruption of the normal kidney architecture [79, 82-84]. AMLs are asymptomatic in most cases, however multiple and large masses are more likely to cause haemorrhage and symptoms such as haematuria and flank pain $[80,85]$.

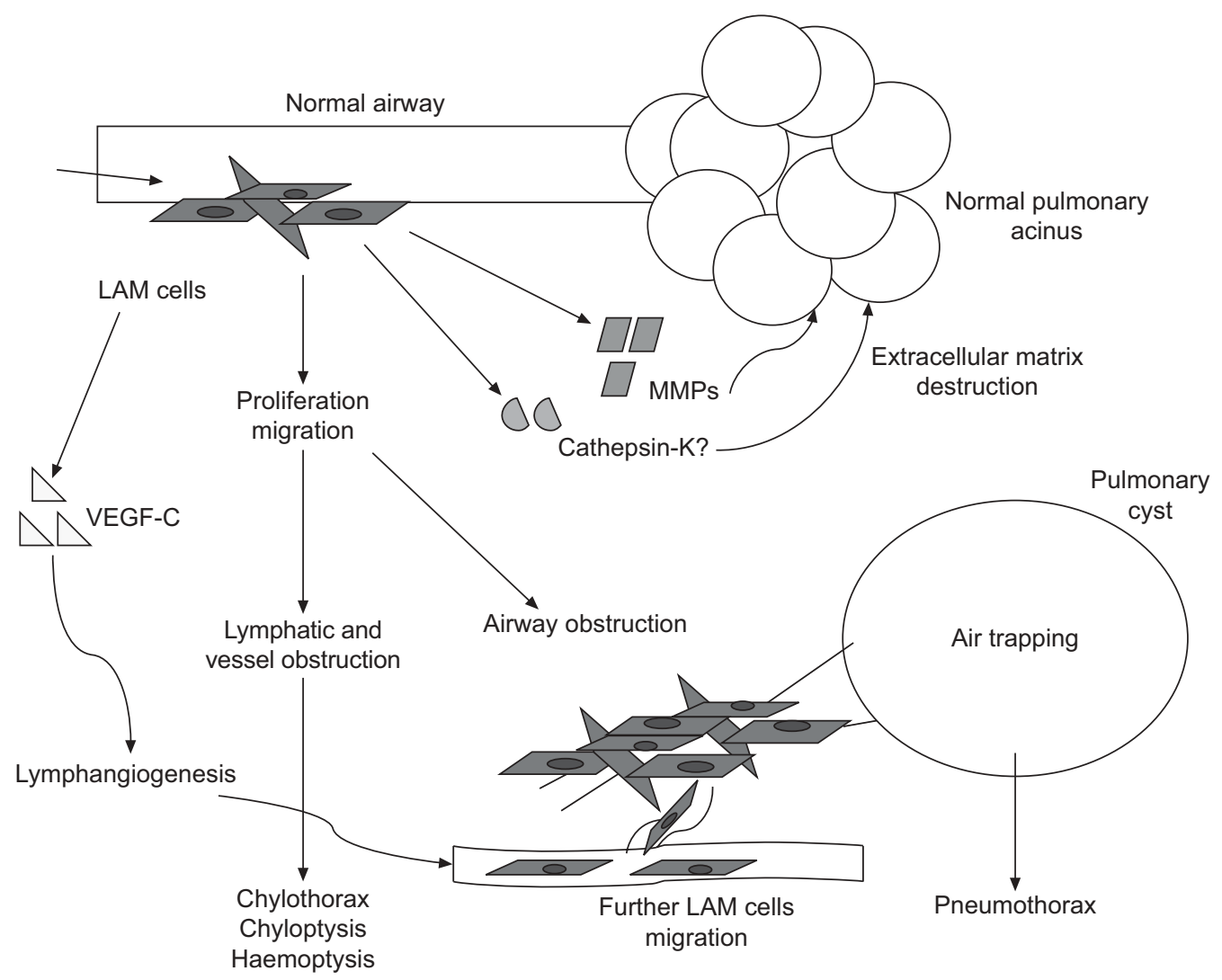

FIGURE 4. Possible mechanisms of lung cysts formation in lymphangioleiomyomatosis (LAM). VEGF: vascular endothelial growth factor; MMP: matrix metalloproteinase. Adapted from [76] with permission from the publisher. 


\begin{tabular}{ll} 
TABLE 1 & $\begin{array}{l}\text { Symptoms and clinical manifestations in } \\
\text { lymphangioleiomyomatosis }\end{array}$ \\
& Patients \% \\
\hline Dyspnoea & 87 \\
Cough & 51 \\
Chest pain & 34 \\
Haemoptysis & 22 \\
Pneumothorax & 65 \\
Chylous effusion & 28 \\
\hline
\end{tabular}

Data are taken from $[1-5,77]$

Enlarged retroperitoneal, retrocrural or occasionally pelvic lymph nodes, are detected by computed tomography (CT) scanning in about $30 \%$ of patients, but are usually asymptomatic [84]. Lymphangioleiomyomas are large cystic tumours primarily occuring in the abdomen, retroperitoneum and pelvis and can been found in up to $10 \%$ of patients [4]. Associated symptoms are nausea, abdominal distension, peripheral oedema and urinary symptoms [86]. Chylous ascites due to lymphatic obstruction and associated with chylous thoracic collections is present in $10 \%$ of patients with more advanced disease [4, 84]. It has been described that meningiomas have an increased prevalence in LAM than in general population, although their relationship with LAM, TSC or therapy with progesterone is unclear. As progesterone has a mitogenic effect on meningiomas, and progesterone receptors are found in these tumours, it has been hypothesised that hormonal therapy with progesterone could have a role in formation or progression of meningiomas [87]. Finally, signs consistent with TSC, such as facial angiofibromas, periungual fibromas, nail ridging and the shagreen

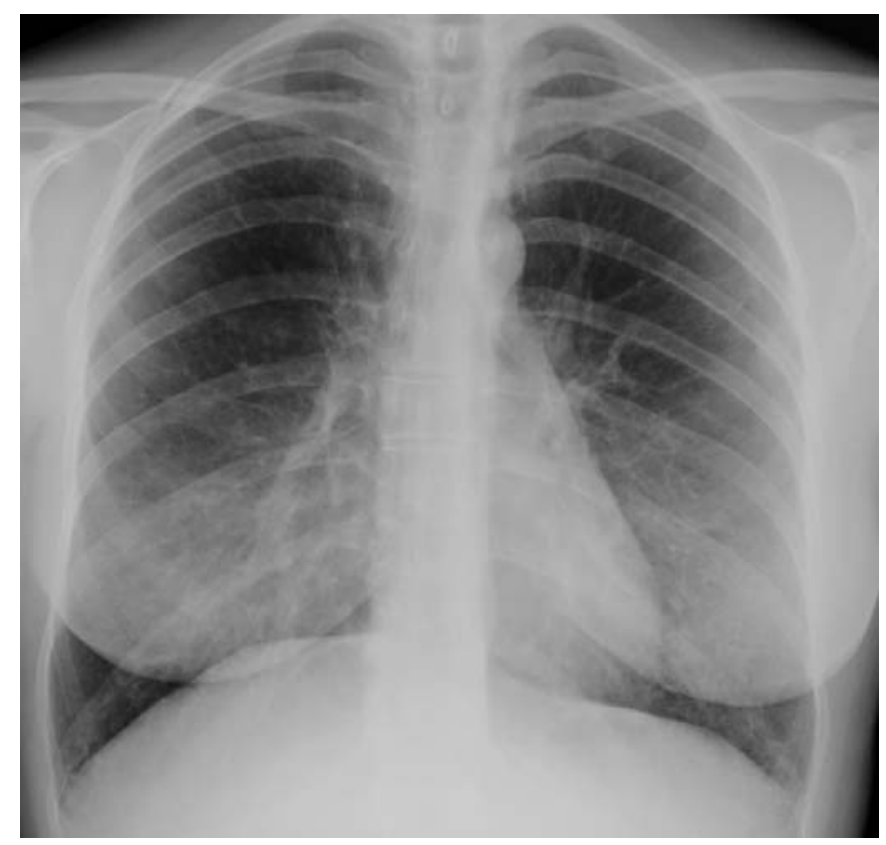

FIGURE 5. Chest radiograph in lymphangioleiomyomatosis showing bilateral reticular changes. patch, are seen in patients with TSC-LAM. As these manifestations may be overlooked in patients with mild disease, a full evaluation may be necessary to confirm the diagnosis when there is a clinical suspicion of TSC [88], comprehensive of brain (usually with magnetic resonance imaging (MRI)) and heart imaging and genetic evaluation.

\section{RADIOLOGICAL FINDINGS}

The chest radiograph often appears normal in early disease, although it may show pleural effusions or pneumothorax. In more advanced disease a reticulonodular pattern and cysts or bullae are the most common findings. (figs 5 and 6) The characteristic abnormality on lung $\mathrm{CT}$ scans in patients with LAM is the presence of well circumscribed, round and thinwalled cysts that are scattered in a bilateral roughly symmetric pattern, without any lobar predominance [89-91]. These cysts range in size from barely perceptible to several centimetres and in number from a few scattered cysts to near complete replacement of the lung parenchyma (fig. 7).

Angiomyolipoma can usually be identified by CT because of the presence of fat, which gives lesions a characteristic CT appearance. MRI may be adequate for the diagnosis when iodinated contrast is contraindicated (fig. 8) [92]. Diagnostic difficulty may arise in the small number of angiomyolipomas showing little evidence of fat; in these cases, tissue biopsy may be necessary to differentiate angiomyolipomas from renal cell carcinoma. Other extrapulmonary findings include lymphangioleiomyomas and ascites [84, 85]. Lymphangioleiomyomas are usually localised in the mediastinum, retroperitoneum, and pelvis along the axial lymphatics and can appear larger in the evening due to accumulation of chyle in the cystic structures [86].

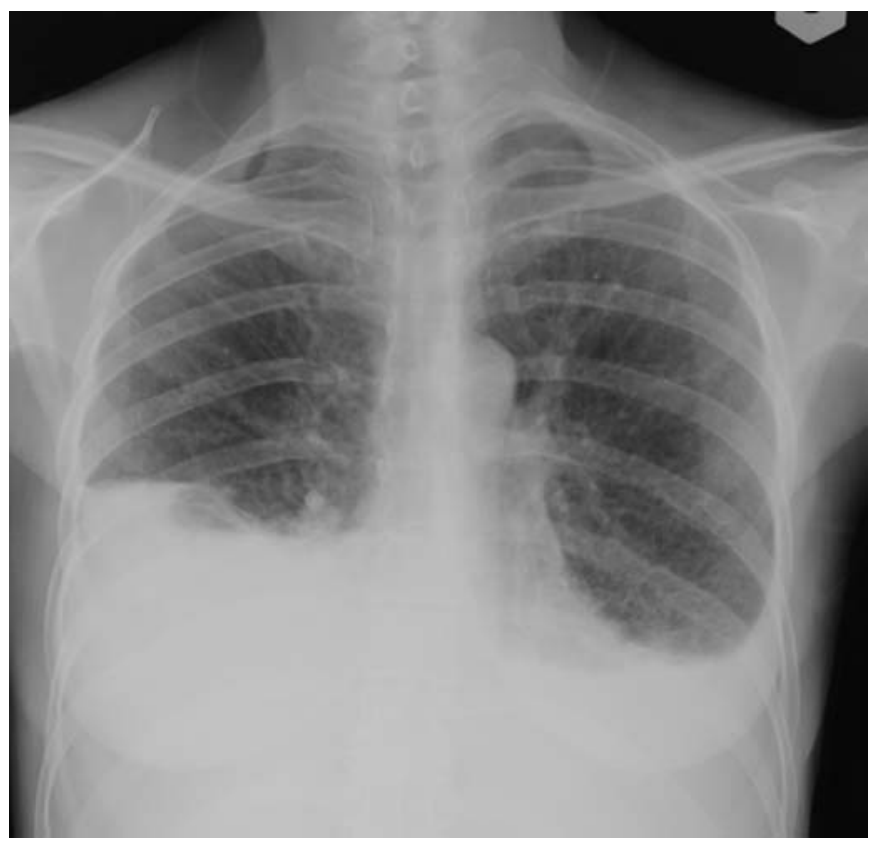

FIGURE 6. Chest radiograph in lymphangioleiomyomatosis showing bilateral pleural effusion and interstitial changes. Thoracentesis confirmed the presence of chylous pleural effusion. 

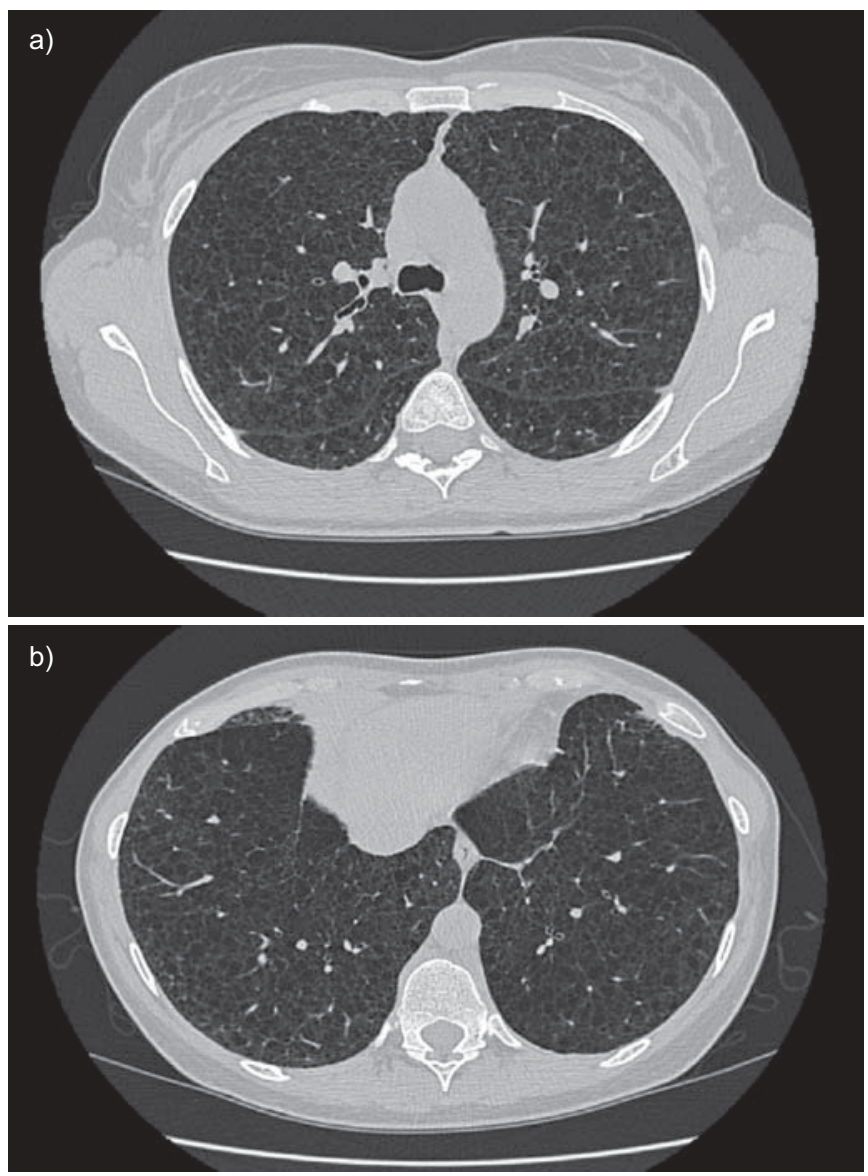

FIGURE 7. High-resolution computed tomography scans of the chest in a patient with histological diagnosis of lymphangioleiomyomatosis. Round shaped thin-walled cysts are distributed diffusely throughout the lungs (a) without sparing of lung bases (b).

\section{DIAGNOSTIC CRITERIA AND DIFFERENTIAL DIAGNOSIS}

Recently, guidelines for the diagnosis, assessment and treatment of LAM have been published by the European Respiratory Society LAM task force [93]. The guidelines highlight diagnostic criteria and management including current available treatment of the disease and its complications.

\section{Diagnostic criteria}

On the basis of pathologic and clinical findings, extrapulmonary manifestations and CT scans the diagnosis of LAM can be define as definite, probable or possible [93]. According to these criteria, a characteristic lung CT in a female renders lung biopsy not necessary for a definite diagnosis if any of the following extrapulmonary manifestations is present: AML, thoracic or abdominal chylous effusion, lymphangioleiomyoma or biopsy-proven lymph node involved by LAM, and definite or probable TSC. High-resolution CT (HRCT) is the recommended imaging technique for LAM. The diagnosis of LAM is probable when a characteristic lung CT is found in a patient with compatible clinical history or when compatible CT features are present in a patient with angiomyolipoma or chylous effusion. Characteristic HRCT findings are multiple (more than 10) thin-walled round well-defined air-filled cysts with no other significant pulmonary involvement with the
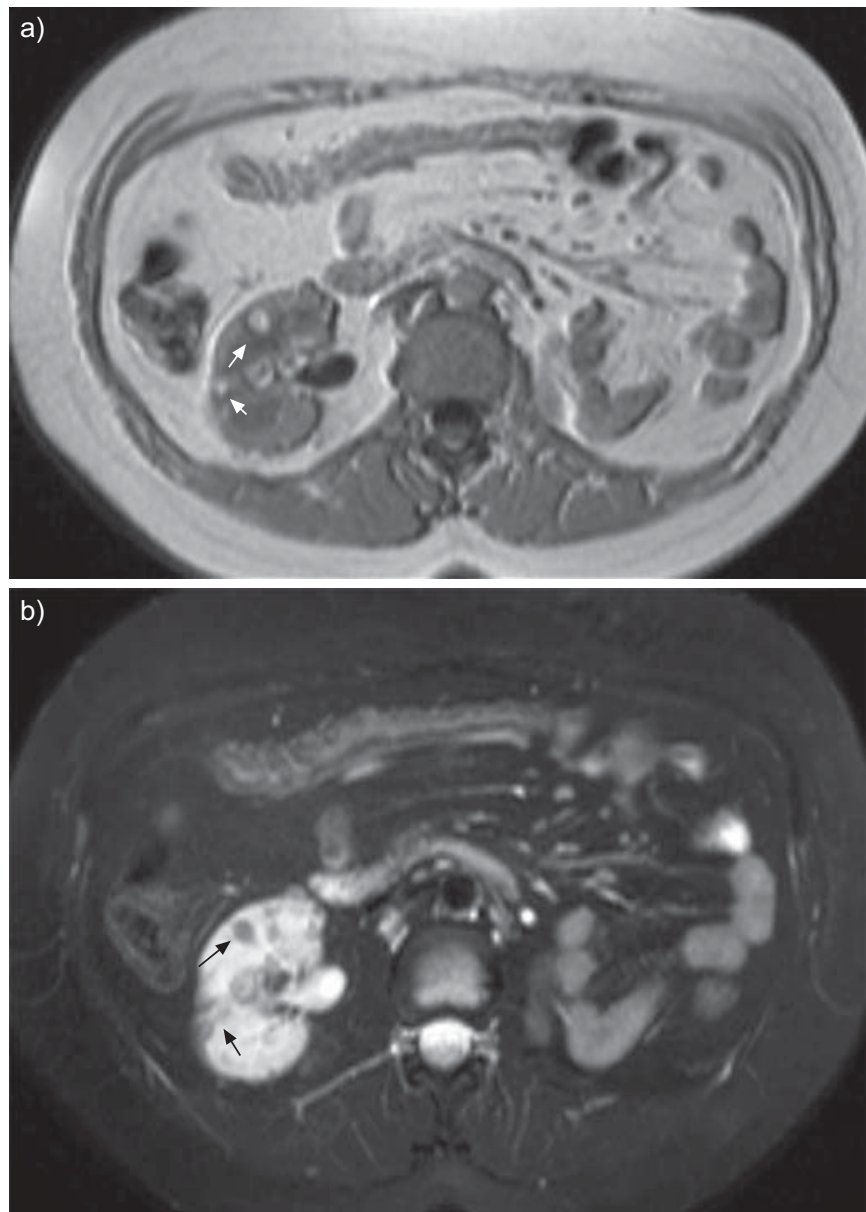

FIGURE 8. Abdominal magnetic resonance imaging of a patient with tuberous sclerosis complex lymphangioleiomyomatosis and multiple small renal angiomyolipomas (arrows) in T1-weighted images (a) and fat suppression signal sequences (b). Left nephrectomy was performed for a large angiomyolipoma.

exception of possible features of multifocal micronodular pneumocyte hyperplasia (a hamartomatous process of the lung that exhibits multiple small nodules) in patients with TSC. When only few (more than two and fewer than 10) typical cysts are present, HRCT features are compatible with pulmonary LAM. Characteristic or compatible HRCT alone with no other suggestive clinical feature makes the diagnosis of LAM possible, but is not sufficient for a definite diagnosis.

\section{Differential diagnosis}

When all criteria for definite LAM are not satisfied, a certain diagnosis of the disease requires exclusion of the alternative causes of cystic lung disease. The primary differential diagnosis includes pulmonary Langerhans cell histiocytosis $(\mathrm{LCH})$ and emphysema. The smoking history and the morphology of the cysts can be helpful in differentiating these disorders from LAM [94-96]. LCH is characterised by irregularly shaped thicker walled cysts, which involve predominantly the middle and upper lobes, and are often associated to nodular lesions. Typical lung parenchyma changes of emphysema are devoid of distinct walls. Less common diseases that should also be considered in differential diagnosis include Sjögren syndrome, lymphocytic interstitial 
pneumonitis, hypersensitivity pneumonitis, amyloidosis, light chain-deposition disease, low-grade leiomyosarcomas, metastatic endometrial stromal cell sarcoma [97-101], and BirtHogg-Dubé (BHD) syndrome, a rare tumour suppressor syndrome that is associated with spontaneous pneumothorax, skin manifestations, pulmonary cysts, and various types of renal tumours [102].

It has been reported that LAM cells express VEGF-D, a lymphangiogenic growth factor. Serum VEGF-D levels have been shown to be higher in patients with LAM than in healthy volunteers and patients with other cystic lung diseases [103]. Therefore, a serum VEGF-D level of $>800 \mathrm{pg} \cdot \mathrm{mL}^{-1}$ in a female with typical lung cystic changes on HRCT scan has been proven to be diagnostically specific for S-LAM and identifies LAM in females with TSC [104]. Finally, its levels have been correlated to more severe disease [105]. Thus, serum VEGF-D may be a useful biomarker for differential diagnosis and prognostic evaluation of LAM.

Finally, LAM can be confused with lymphangiomatosis, a rare disease that is associated with abdominal and thoracic lymphatic smooth muscle infiltration, lymphadenopathy and lymphangiomas and can involve the lung. But as opposed to LAM, it affects both males and females and does not generate lung cysts [106].

\section{TREATMENT}

\section{Pulmonary and abdominal complications}

Conservative treatment could be the initial approach to pneumothorax. But if the air leak persists or if the pneumothorax recurs, surgical pleurodesis should be performed; as an alternative chemical pleurodesis may be performed in individual casesin [107]. Chylothorax is often difficult to treat and pleurodesis is frequently necessary, a low-fat diet and therapeutic thoracentesis may be the initial approach [79, 108]. Thoracic duct ligation has also been performed safely in LAM. Octreotide is a long-acting somatostatin analogue that slows the production of chyle through reduction in splanchnic blood flow. Although case reports and series have shown that octreotide is probably effective for the treatment of chylous complications in other diseases $[109,110]$, it can cause gallstones and the experience is too limited to recommend it in LAM patients.

Asymptomatic small renal AML $(<4 \mathrm{~cm})$ should not be treated; yearly follow-up should be performed by ultrasound, or CT or MRI when ultrasound measurements are unreliable due to technical factors. Larger asymptomatic AML at an increased risk for bleeding should be followed twice yearly to evaluate growth [93]. Symptomatic AMLs should be treated as conservatively as possible to preserve renal function. Both embolisations and nephron sparing surgery have been performed safely $[79,111]$. Although no trials have compared the two strategies, embolisation may be preferred in patients with active bleeding, while nephron sparing surgery may be used when a malignant lesion is suspected [93].

A proven therapeutic intervention is not currently available for lymphangioleiomyomas.

Treatment with bronchodilators is recommended for $20 \%$ of patients who have a significant positive response to bronchodilators $[112,113]$; there is no evidence that corticosteroids are helpful.
Oxygen, where appropriate, pulmonary rehabilitation and prophylactic vaccinations are other important measures.

\section{Hormonal therapy}

At present no effective treatment for LAM is available. Since LAM affects predominantly pre-menopausal females and can worsen during pregnancy, and after the administration of oestrogens $[114,115]$, various hormonal strategies have been used in the treatment of the disease. Effects of bilateral oophorectomy are controversial, and there is no objective evidence of improvement with anti-oestrogen therapy $[78,116]$. There have been reports of improvement with Gonadotrophin-releasing hormone $(\mathrm{GnRH})$ analogues but other studies were inconclusive and no placebo-controlled clinical trials on GnRH analogues are available [117-121].

The use of progesterone became the standard of care after a series of case reports and clinical studies [122, 123]. A retrospective study found a nonsignificant reduction in the rate of decline in forced expiratory volume in $1 \mathrm{~s}$ (FEV1) and a significant reduction in the rate of decline in carbon monoxide diffusing capacity of the lung $(D \mathrm{~L}, \mathrm{CO})$ in patients treated with progesterone compared with untreated patients [124]. Another retrospective study of 275 patients with LAM showed that the overall yearly rates of decline of FEV1 and DL,CO for patients who received oral or intramuscular progesterone were not significantly different from patients who were not treated with progesterone [125]. There have been no controlled trials of progesterone in patients with LAM.

In conclusion, hormone treatment should be discouraged except in individual cases with rapid progression of the disease in which progesterone may be trialled.

\section{Future therapeutic issues}

Recent progress in our understanding of the molecular pathogenesis of LAM and muscle cell biology provides a foundation for the development of new therapeutic strategies. Inhibitors of mTOR and inhibitors of MMPs and angiogenesis are the most promising areas of research.

\section{Inhibitors of mTOR}

Sirolimus is an antifungal macrolide antibiotic currently in use for the prevention of allograft rejection after solid organ transplantation. Because of its inhibitory effect of mTORmediated proliferation and growth of LAM cells in vitro, it has been studied as a possible treatment for LAM.

The Cincinnati Angiomyolipoma Sirolimus Trial was a pilot study involving 25 patients with AMLs, including 18 with LAM. After 1 yr receiving sirolimus, AML volume decreased by almost $50 \%$, and airflow measurements of FEV1 and forced vital capacity increased by 5 to $10 \%$ [126]. The improvements in AML and FEV1 were reduced after therapy cessation but not back to baseline values. Interim analysis of a similar trial in seven patients with TSC and six patients with S-LAM showed analogous results regarding AML volume [127]. In both studies there were adverse events such as frequent aphthous ulcers, diarrhoea and upper respiratory infections. FEV1 response is the primary outcome of the Multicenter International LAM Efficacy of Sirolimus (MILES) Trial, a larger, randomised controlled trial which opened in 2006. 
mTOR inhibitors can regulate major functional activities of osteoclasts, including the production of cathepsin-K whose expression has been recently found to be strongly present in LAM cells [70], as mentioned above. Thus, it is possible to speculate that mTOR inhibitors may exert part of their action also by limiting the destructive remodelling of lung structure.

An open-label, nonrandomised, within-subject dose escalation safety, tolerability and efficacy study of everolimus (a second generation mTOR inhibitor) in females with sporadic or TSCLAM is ongoing.

\section{Inhibitors of MMPs and angiogenesis}

Doxycyline, an inhibitor of MMPs [128], may be an efficacious treatment of pulmonary capillary haemangiomatosis [129], a disorder in which angiogenesis is related to MMP activity. Recently, Moses et al. [130] reported a case of a patient with advanced pulmonary LAM whose FEV1 and levels of oxygen saturation at rest and on exercise significantly improved in association with reduction of urinary MMPs after treatment with doxycycline. Further studies are required to confirm this interesting observation, and a clinical trial is now ongoing in UK.

Another possible target for future treatment of LAM is lymphangiogenesis. Recent data on mice suggest that the crucial angiogenic factor VEGF may be important in the progression of LAM lesions [131]. Moreover, results in a series of surgical and autopsy cases of LAM showed that VEGF-C is overexpressed in LAM lesions where it is associated with the excessive growth of lymphatics [74]. VEGF-D was elevated in the serum of patients with LAM and may be a biomarker for the disease [102]. Antibody inhibitors of VEGF pathways have been developed and some are in clinical trials for different solid tumours [132-134].

Other potential targets in LAM include the farnesylated protein Rheb and growth factor receptor tyrosine kinases located upstream of the deregulated hamartin-tuberin-mTOR pathway. Imanitib, an effective tyrosine kinase inhibitor, and farnesyltransferase inhibitors targeting Rheb may be objects for further studies [53, 135, 136]. Statins, which inhibit 3hydroxy-3-methylglutaryl-coenzymeA (HMGCoA), have been found to inhibit the growth of TSC2 ${ }^{-/-}$cells in vitro, although, to date, no therapeutic effect has been found with statins in in vivo studies of TSC disease. Furthermore a retrospective review of 335 patients with LAM showed a significantly greater yearly rate of decline of $D \mathrm{~L}, \mathrm{CO} \%$ predicted in LAM patients on statins in comparison with their matched controls [137].

As for other rare diseases, research into LAM has been strongly limited by a relative inability to capture sufficiently large patient populations. The recently established international LAM registry is a component of a set of web-based resources, including a patient self-report data portal, aimed at accelerating research in rare diseases in a rigorous fashion and is an example of how such a collaboration between clinicians, researchers, advocacy groups and patients can create an essential community resource infrastructure, and thus accelerate rare disease research [138].

\section{SUPPORT STATEMENT}

J. Moss was supported by the Intramural Research Program, National Institutes of Health, National Heart, Lung, and Blood Institute, Bethesda, MD, USA.

\section{STATEMENT OF INTEREST}

None declared.

\section{REFERENCES}

1 Kitaichi M, Nishimura K, Itoh $\mathrm{H}$, et al. Pulmonary lymphangiomyomatosis: a report of 46 patients including a clinicopathologic study of prognostic factors. Am J Respir Crit Care Med 1995; 151: 527-533

2 Urban T, Lazor R, Lacronique J, et al. Pulmonary lymphangioleiomyomatosis: a study of 69 patients. Groupe d'Etudes et de Recherche sur les Maladies "Orphelines" Pulmonaires (GERM" $\mathrm{O}$ ”P). Medicine (Baltimore) 1999; 78: 321-337.

3 Chu SC, Horiba K, Usuki J, et al. Comprehensive evaluation of 35 patients with lymphangioleiomyomatosis. Chest 1999; 115: 1041-1052.

4 Johnson SR, Tattersfield AE. Clinical experience of lymphangioleiomyomatosis in the UK. Thorax 2000; 55: 1052-1057.

5 Ryu JH, Moss J, Beck GJ, et al. The NHLBI Lymphangioleiomyomatosis Registry: characteristics of 230 patients at enrollment. Am J Respir Crit Care Med 2006; 173: 105-111.

6 Costello LC, Hartman TE, Ryu JH. High frequency of pulmonary lymphangioleiomyomatosis in women with tuberous sclerosis complex. Mayo Clin Proc 2000; 75: 591-594.

7 Franz DN, Brody A, Meyer C, et al. Mutational and radiographic analysis of pulmonary disease consistent with lymphangioleiomyomatosis and micronodular pneumocyte hyperplasia in women with tuberous sclerosis. Am J Respir Crit Care Med 2001; 164: 661-668.

8 Moss J, Avila NA, Barnes PM, et al. Prevalence and clinical characteristics of lymphangioleiomyomatosis (LAM) in patients with tuberous sclerosis complex. Am J Respir Crit Care Med 2001; 164: 669-671.

9 Sparagana SP, Roach ES. Tuberous sclerosis complex. Curr Opin Neurol 2000; 13: 115-119.

10 Juvet SC, McCormack FX, Kwiatkowski DJ, et al. Molecular pathogenesis of lymphangioleiomyomatosis: lessons learned from orphans. Am J Respir Cell Mol Biol 2006; 38: 398-408.

11 Taveira-DaSilva AM, Moss J. Lymphangioleiomyomatosis. Cancer Control 2006; 13: 276-285.

12 Zhe X, Schuger L. Combined smooth muscle and melanocytic differentiation in lymphangioleiomyomatosis. I Histochem Cytochem 2004; 52: 1537-1542.

13 Matsumoto Y, Horiba K, Usuki J, et al. Markers of cell proliferation and expression of melanosomal antigen in lymphangioleiomyomatosis. Am J Respir Cell Mol Biol 1999; 21: 327-336.

14 Finlay G. The LAM cell: what is it, where does it come from, and why does it grow? Am J Physiol Lung Cell Mol Physiol 2004; 286: L690-L693.

15 Brentani MM, Carvalho CR, Saldiva PH, et al. Steroid receptors in pulmonary lymphangiomyomatosis. Chest 1984; 85: 96-99.

16 Logginidou H, Ao X, Russo I, et al. Frequent estrogen and progesterone receptor immunoreactivity in renal angiomyolipomas from women with pulmonary lymphangioleiomyomatosis. Chest 2000; 117: 25-30

17 Barberis M, Monti GP, Ziglio G, et al. Oestrogen and progesterone receptors detection in pulmonary lymphangioleiomyomatosis. Am J Respir Crit Care Med 1996; 153: 271.

18 Pea M, Bonetti F, Zamboni G, et al. Melanocyte-marker-HMB-45 is regularly expressed in angiomyolipoma of the kidney. Pathology 1991; 23: 185-188.

19 Avila NA, Dwyer AJ, Rabel A, et al. Sporadic lymphangioleiomyomatosis and tuberous sclerosis complex with lymphangioleiomyomatosis: comparison of CT features. Radiology 2007; 242: 277-285. 
20 Bissler JJ, Kingswood JC. Renal angiomyolipomata. Kidney Int 2004; 66: 924-934.

21 Kwiatkowski DJ. Tuberous sclerosis: from tubers to mTOR. Ann Hum Genet 2003; 67: 87-96.

22 Crooks DM, Pacheco-Rodriguez G, DeCastro RM, et al. Molecular and genetic analysis of disseminated neoplastic cells in lymphangioleiomyomatosis. Proc Natl Acad Sci USA 2004; 101: 17462-17467.

23 Karbowniczek M, Astrinidis A, Balsara BR, et al. Recurrent lymphangiomyomatosis after transplantation: genetic analyses reveal a metastatic mechanism. Am J Respir Crit Care Med 2003; 167: 976-982.

$24 \mathrm{Yu} \mathrm{J}$, Astrinidis A, Henske EP. Chromosome 16 loss of heterozygosity in tuberous sclerosis and sporadic lymphangiomyomatosis. Am J Respir Crit Care Med 2001; 164: 1537-1540.

25 Sato T, Seyama K, Fujii H, et al. Mutational analysis of the TSC1 and TSC2 genes in Japanese patients with pulmonary lymphangileiomyomatosis. J Hum Genet 2002; 47: 20-28.

26 Smolarek TA, Wessner LL, McCormack FX, et al. Evidence that lymphangiomyomatosis is caused by TSC2 mutations: chromosome $16 \mathrm{p} 13$ loss of heterozygosity in angiomyolipomas and lymph nodes from women with lymphangiomyomatosis. Am J Hum Genet 1998; 62: 810-815.

27 Carsillo T, Astrinidis A, Henske EP. Mutations in the tuberous sclerosis complex gene TSC2 are a cause of sporadic pulmonary lymphangioleiomyomatosis. Proc Natl Acad Sci USA 2000; 97: 6085-90.

28 Knudson AG Jr. Mutation and cancer: statistical study of retinoblastoma. Proc Natl Acad Sci USA 1971; 68: 820-823.

29 van Slegtenhorst M, de Hoogt R, Hermans C, et al. Identification of the tuberous sclerosis gene TSC1 on chromosome 9q34. Science 1997; 277: 805-808.

30 The European Chromosome 16 Tuberous Sclerosis Consortium. Identification and characterization of the tuberous sclerosis gene on chromosome 16. Cell 1993; 75: 1305-1315.

31 Rosner M, Freilinger A, Hengstschlager M. Proteins interacting with the tuberous sclerosis gene products. Amino Acids 2004; 27: 119-128.

32 Lamb RF, Roy C, Diefenbach TJ, et al. The TSC1 tumour suppressor hamartin regulates cell adhesion through ERM proteins and the GTPase Rho. Nat Cell Biol 2000; 2: 281-287.

33 Haddad LA, Smith N, Bowser M, et al. The TSC1 tumor suppressor hamartin interacts with neurofilament-L and possibly functions as a novel integrator of the neuronal cytoskeleton. J Biol Chem 2002; 277: 44180-44186.

34 van Slegtenhorst M, Nellist M, Nagelkerken B, et al. Interaction between hamartin and tuberin, the TSC1 and TSC2 gene products. Hum Mol Genet 1998; 7: 1053-1057.

35 Maheshwar MM, Sandford R, Nellist M, et al. Comparative analysis and genomic structure of the tuberous sclerosis 2 (TSC2) gene in human and pufferfish. Hum Mol Genet 1996; 5: 131-137.

36 Dan HC, Sun M, Yang L, et al. Phosphatidylinositol 3-kinase/Akt pathway regulates tuberous sclerosis tumor suppressor complex by phosphorylation of tuberin. J Biol Chem 2002; 277: 35364-35370.

37 Inoki K, Li Y, Zhu T, et al. TSC2 is phosphorylated and inhibited by Akt and suppresses mTOR signalling. Nat Cell Biol 2002; 4: 648-657.

38 Ma L, Chen Z, Erdjument-Bromage H, et al. Phosphorylation and functional inactivation of TSC2 by Erk implications for tuberous sclerosis and cancer pathogenesis. Cell 2005; 121: 179-193.

39 Li Y, Inoki K, Vacratsis P, et al. The p38 and MK2 kinase cascade phosphorylates tuberin, the tuberous sclerosis 2 gene product, and enhances its interaction with 14-3-3. J Biol Chem 2003; 278: 13663-13671.

40 Roux PP, Ballif BA, Anjum R, et al. Tumor-promoting phorbol esters and activated Ras inactivate the tuberous sclerosis tumor suppressor complex via p90 ribosomal S6 kinase. Proc Natl Acad Sci USA 2004; 101: 13489-13494.

41 Soucek T, Pusch $\mathrm{O}$, Wienecke R, et al. Role of the tuberous sclerosis gene-2 product in cell cycle control. J Biol Chem 1997; 272: 29301-29308.

42 Lamb RF, Roy C, Diefenbach TJ, et al. The TSC1 tumour suppressor hamartin regulates cell adhesion through ERM proteins and the GTPase Rho. Nat Cell Biol 2000; 2: 281-287.

43 Johnson MW, Emelin JK, Park SH, et al. Co-localization of TSC1 and TSC2 gene products in tubers of patients with tuberous sclerosis. Brain Pathol 1999; 9: 45-54.

44 Fukuda T, Kobayashi T, Momose S, et al. Distribution of Tsc1 protein detected by immunohistochemistry in various normal rat tissues and the renal carcinomas of Eker rat: detection of limited colocalization with Tsc1 and Tsc2 gene products in vivo. Lab Invest 2000; 80: 1347-1359.

45 Johnson MW, Kerfoot C, Bushnell T, et al. Hamartin and tuberin expression in human tissues. Mod Pathol 2001; 14: 202-210.

46 Catania MG, Johnson MW, Liau LM, et al. Hamartin expression and interaction with tuberin in tumor cell lines and primary cultures. J Neurosci Res 2001; 63: 276-283.

47 Schmelzle T, Hall MN. TOR, a central controller of cell growth. Cell 2000; 103: 253-262.

48 Barbet NC, Schneider U, Helliwell SB, et al. TOR controls translation initiation and early G1 progression in yeast. Mol Biol Cell 1996; 7: 25-42.

49 Garami A, Zwartkruis FJ, Nobukuni T, et al. Insulin activation of Rheb, a mediator of mTOR/S6K/4E-BP signaling, is inhibited by TSC1 and 2. Mol Cell 2003; 11: 1457-1466.

50 Inoki $\mathrm{K}$, Li Y, Xu T, et al. Rheb GTPase is a direct target of TSC2 GAP activity and regulates mTOR signaling. Genes Dev 2003; 17 1829-1834.

51 Saucedo LJ, Gao X, Chiarelli DA, et al. Rheb promotes cell growth as a component of the insulin/TOR signaling network. Nat Cell Biol 2003; 5: 566-571.

52 Zhang Y, Gao X, Saucedo LJ, et al. Rheb is a direct target of the tuberous sclerosis tumour suppressor proteins. Nat Cell Biol 2003; 5: 578-581.

$53 \mathrm{Li} \mathrm{Y,} \mathrm{Inoki} \mathrm{K,} \mathrm{Guan} \mathrm{KL.} \mathrm{Biochemical} \mathrm{and} \mathrm{functional} \mathrm{character-}$ izations of small GTPase Rheb and TSC2 GAP activity. Mol Cell Biol 2004; 24: 7965-7975.

54 Nellist M, Sancak O, Goedbloed MA, et al. Distinct effects of single amino-acid changes to tuberin on the function of the tuberin-hamartin complex. Eur J Hum Genet 2005; 13: 59-68.

55 Dan HC, Sun M, Yang L, et al. Phosphatidylinositol 3-kinase/Akt pathway regulates tuberous sclerosis tumor suppressor complex by phosphorylation of tuberin. J Biol Chem 2002; 277: 35364-35370.

56 Inoki K, Li Y, Zhu T, et al. TSC2 is phosphorylated and inhibited by Akt and suppresses mTOR signalling. Nat Cell Biol 2002; 4: 648-657.

57 Ma L, Chen Z, Erdjument-Bromage H, et al. Phosphorylation and functional inactivation of TSC2 by Erk implications for tuberous sclerosis and cancer pathogenesis. Cell 2005; 121: 179-193.

58 Li Y, Inoki K, Vacratsis P, et al. The p38 and MK2 kinase cascade phosphorylates tuberin, the tuberous sclerosis 2 gene product, and enhances its interaction with 14-3-3. J Biol Chem 2003; 278: 13663-13671.

59 Inoki K, Zhu T, Guan KL. TSC2 mediates cellular energy response to control cell growth and survival. Cell 2003; 115: 577-590.

60 Finlay GA, York B, Karas RH, et al. Estrogen-induced smooth muscle cell growth is regulated by tuberin and associated with altered activation of platelet-derived growth factor receptor-beta and ERK-1/2. J Biol Chem 2004; 279: 23114-23122.

61 Simoncini T, Hafezi-Moghadam A, Brazil DP, et al. Interaction of oestrogen receptor with the regulatory subunit of phophastidylinositol-3-OH kinase. Nature 2000; 407: 538-541. 
62 Flores-Delgado G, Anderson KD, Warburton D. Nongenomic estrogen action regulates tyrosine phosphatase activity and tuberin stability. Mol Cell Endocrinol 2003; 199: 143-151.

$63 \mathrm{Yu} \mathrm{J}$, Astrinidis A, Howard S, et al. Estradiol and tamoxifen stimulate LAM-associated angiomyolipoma cell growth and activate both genomic and nongenomic signaling pathways. Am J Physiol Lung Cell Mol Physiol 2004; 286: L694-L700.

64 York B, LouD, Panettieri RA Jr, et al. Cross-talk between tuberin, calmodulin, and estrogen signaling pathways. FASEB J 2005; 19: 1202-1204.

$65 \mathrm{Yu}$ JJ, Robb VA, Morrison TA, et al. Estrogen promotes the survival and pulmonary metastasis of tuberin-null cells. Proc Natl Acad Sci USA 2009 Feb 24, 106: 2635-2640.

66 Crawford HC, Matrisian LM. Tumor and stromal expression of matrix metalloproteinases and their role in tumor progression. Invasion Metastasis 1994; 14: 234-245.

67 Matsui K, Takeda K, Yu ZX, et al. Downregulation of estrogen and progesterone receptors in the abnormal smooth muscle cells in pulmonary lymphangioleiomyomatosis following therapy: an immunohistochemical study. Am J Respir Crit Care Med 2000; 161: 1002-1009.

68 Matsui K, Takeda K, Yu ZX, et al. Role for activation of matrix metalloproteinases in the pathogenesis of pulmonary lymphangioleiomyomatosis. Arch Pathol Lab Med 2000; 124: 267-275.

69 Hayashi T, Fleming MV, Stetler-Stevenson WG, et al. Immunohistochemical study of matrix metalloproteinases (MMPs) and their tissue inhibitors (TIMPs) in pulmonary lymphangioleiomyomatosis (LAM). Hum Pathol 1997; 28: 1071-1078.

70 Chilosi M, Pea M, Martignoni G, et al. Cathepsin-K expression in pulmonary lymphangioleiomyomatosis. Mod Pathol 2009; 22 161-166.

71 Bromme D, Okamoto K, Wang BB, et al. Humancathepsin O2, a matrix protein-degrading cysteine protease expressed in osteoclasts. Functional expression of human cathepsin $\mathrm{O} 2$ in Spodoptera frugiperda and characterization of the enzyme. J Biol Chem 1996; 271: 2126-2132.

72 Merrilees MJ, Hankin EJ, Black JL, et al. Matrix proteoglycans and remodelling of interstitial lung tissue in lymphangioleiomyomatosis. J Pathol 2004; 203: 653-660.

73 Kumasaka T, Seyama K, Mitani K, et al. Lymphangiogenesis in lymphangioleiomyomatosis: its implication in the progression of lymphangioleiomyomatosis. Am J Surg Pathol 2004; 28: 1007-1016.

74 Kumasaka T, Seyama K, Mitani K, et al. Lymphangiogenesis mediated shedding of LAM cell clusters as a mechanism for dissemination in lymphangioleiomyomatosis. Am J Surg Pathol 2005; 29: 1356-1366.

75 Travis WD, Usuki J, Horiba K, et al. Histopathologic studies on lymphangioleiomyomatosis. In: Moss J, ed. LAM and other Diseases Characterized by Smooth Muscle Proliferation. New York, Marcel Dekker, Inc., 1999; pp. 171-217.

76 Juvet SC, McCormack FX, Kwiatkowski DJ, et al. Molecular pathogenesis of lymphangioleiomyomatosis. Am J Respir Cell Mol Biol 2007; 36: 398-408.

77 Taveira-Dasilva AM, Stylianou MP, Hedin CJ, et al. Bone mineral density in lymphangioleiomyomatosis. Am J Respir Crit Care Med 2005; 171: 61-67.

78 Taylor JR, Ryu J, Colby TV, et al. Lymphangioleiomyomatosis. Clinical course in 32 patients. N Engl J Med 1990; 323: 1254-1260.

79 Ryu JH, Doerr CH, Fisher SD, et al. Chylothorax in lymphangioleiomyomatosis. Chest 2003; 123: 623-627.

80 Bissler JJ, Kingswood JC. Renal angiomyolipomata. Kidney Int 2004; 66: 924-934.

81 L'Hostis H, Deminiere C, Ferriere JM, et al. Renal angiomyolipoma: a clinicopathologic, immunohistochemical, and follow-up study of 46 cases. Am J Surg Pathol 1999; 23: 1011-1020.
82 Bernstein SM, Newell JD Jr, Adamczyk D, et al. How common are renal angiomyolipomas in patients with pulmonary lymphangiomyomatosis? Am J Respir Crit Care Med 1995; 152: 2138-2143.

83 Maziak DE, Kesten S, Rappaport DC, et al. Extrathoracic angiomyolipomas in lymphangioleiomyomatosis. Eur Respir J 1996; 9: 402-405.

84 Avila NA, Kelly JA, Chu SC, et al. Lymphangioleiomyomatosis: abdominopelvic CT and US findings. Radiology 2000; 216: 147-153.

85 Matsui K, Tatsuguchi A, Valencia J, et al. Extrapulmonary lymphangioleiomyomatosis (LAM): clinicopathologic features in 22 cases. Hum Pathol 2000; 31: 1242-1248.

86 Avila NA, Bechtle J, Dwyer AJ, et al. Lymphangioleiomyomatosis: $\mathrm{CT}$ of diurnal variation of lymphangioleiomyomas. Radiology 2001; 221: 415-421.

87 Moss J, DeCastro R, Patronas NJ, et al. Meningiomas in lymphangioleiomyomatosis. JAMA 2001; 286: 1879-1881.

88 Roach ES, DiMario FJ, Kandt RS, et al. Tuberous Sclerosis Consensus Conference: recommendations for diagnostic evaluation. National Tuberous Sclerosis Association. J Child Neurol 1999; 14: 401-407.

89 Merchant RN, Pearson MG, Rankin RN, et al. Computerized tomography in the diagnosis of lymphangioleiomyomatosis. Am Rev Respir Dis 1985; 131: 295-297.

90 Avila NA, Chen CC, Chu SC, et al. Pulmonary lymphangioleiomyomatosis: correlation of ventilation-perfusion scintigraphy, chest radiography, and CT with pulmonary function tests. Radiology 2000; 214: 441-446.

91 Avila NA, Kelly JA, Dwyer AJ, et al. Lymphangioleiomyomatosis: correlation of qualitative and quantitative thin-section CT with pulmonary function tests and assessment of dependence on pleurodesis. Radiology 2002; 223: 189-197.

92 Helenon $\mathrm{O}$, Merran S, Paraf F, et al. Unusual fat-containing tumors of the kidney: a diagnostic dilemma. Radiographics 1997; 17: 129-144

93 Johnson SR, Cordier JF, Lazor R, et al. European Respiratory Society guidelines for the diagnosis and management of lymphangioleiomyomatosis. Eur Respir J 2010; 35: 14-26.

94 Koyama M, Johkoh $\mathrm{T}$, Honda $\mathrm{O}$, et al. Chronic cystic lung disease: diagnostic accuracy of high-resolution CT in 92 patients. AJR Am J Roentgenol 2003; 180: 827-835.

95 Harari S, Paciocco G. An integrated clinical approach to diffuse cystic lung diseases. Sarcoidosis Vasc Diffuse Lung Dis 2005; 22 Suppl. 1, S31-S39.

96 Paciocco G, Uslenghi E, Bianchi A, et al. Diffuse cystic lung diseases: correlation between radiologic and functional status. Chest 2004; 125: 135-142.

97 Jeong YJ, Lee KS, Chung MP, et al. Amyloidosis and lymphoproliferative disease in Sjogren syndrome: thin-section computed tomography findings and histopathologic comparisons. J Comput Assist Tomogr 2004; 28: 776-781.

98 Johkoh T, Muller NL, Pickford HA, et al. Lymphocytic interstitial pneumonia: thin-section CT findings in 22 patients. Radiology 1999; 212: 567-572.

99 Silva CI, Churg A, Muller NL. Hypersensitivity pneumonitis: spectrum of high-resolution CT and pathologic findings. AJR Am J Roentgenol 2007; 188: 334-344.

100 Colombat M, Stern M, Groussard O, et al. Pulmonary cystic disorder related to light chain deposition disease. Am J Respir Crit Care Med 2006; 173: 777-780.

101 Aubry MC, Myers JL, Colby TV, et al. Endometrial stromal sarcoma metastatic to the lung: a detailed analysis of 16 patients. Am J Surg Pathol 2002; 26: 440-449.

102 Ayo DS, Aughenbaugh GL, Yi ES, et al. Cystic lung disease in Birt-Hogg-Dube syndrome. Chest 2007; 132: 679-684 
103 Young LR, Inoue J, McCormack FX. Diagnostic potential of serum VEGF-D for lymphangioleiomyomatosis. $N$ Engl J Med 2008; 358: 199-200.

104 Young LR, Vandyke R, Gulleman PM, et al. Serum vascular endothelial growth factor-D prospectively distinguishes lymphangioleiomyomatosis from other diseases. Chest 2010; 138: 674-681.

105 Glasgow CG, Avila NA, Lin JP, et al. Serum vascular endothelial growth factor-D levels in patients with lymphangioleiomyomatosis reflect lymphatic involvement. Chest 2009; 135: 1293-1300.

106 Faul JL, Berry GJ, Colby TV, et al. Thoracic lymphangiomas,lymphangiectasis, lymphangiomatosis, and lymphatic dysplasia syndrome. Am J Respir Crit Care Med 2000; 161: 1037-1046.

107 Almoosa KF, Ryu JH, Mendez J, et al. Management of pneumothorax in lymphangioleiomyomatosis: effects on recurrence and lung transplantation complications. Chest 2006; 129: 1274-1281.

108 Almoosa KF, McCormack FX, Sahn SA. Pleural disease in lymphangioleiomyomatosis. Clin Chest Med 2006; 27: 355-368.

109 Kalomenidis I. Octreotide and chylothorax. Curr Opin Pulm Med 2006; 12: 264-267.

110 Demos NJ, Kozel J, Scerbo JE. Somatostatin in the treatment of chylothorax. Chest 2001; 119: 964-966.

111 Hsu TH, O'Hara J, Mehta A, et al. Nephron-sparing nephrectomy for giant renal angiomyolipoma associated with lymphangioleiomyomatosis. Urology 2002; 59: 138.

112 Taveira-DaSilva AM, Hedin C, Stylianou MP, et al. Reversible airflow obstruction, proliferation of abnormal smooth muscle cells, and impairment of gas exchange as predictors of outcome in lymphangioleiomyomatosis. Am J Respir Crit Care Med 2001; 164: 1072-1076.

113 Taveira-DaSilva AM, Steagall WK, Rabel A, et al. Reversible airflow obstruction in lymphangioleiomyomatosis. Chest 2009; 136: 1596-1603.

114 Brunelli A, Catalini G, Fianchini A. Pregnancy exacerbating unsuspected mediastinal lymphangioleiomyomatosis and chylothorax. Int J Gynaecol Obstet 1996; 52: 289-290.

115 Yano S. Exacerbation of pulmonary lymphangioleiomyomatosis by exogenous oestrogen used for infertility treatment. Thorax 2002; 57: 1085-1086.

116 Eliasson AH, Phillips YY, Tenholder MF. Treatment of lymphangioleiomyomatosis: a meta-analysis. Chest 1989; 96: 1352-1355.

117 Rossi GA, Balbi B, Oddera S, et al. Response to treatment with an analog of luteinizing-hormone-releasing hormone in a patient with pulmonary lymphangioleiomyomatosis. Am Rev Respir Dis 1991; 143: 174-176.

118 Medeiros P Jr, Kairalla RA, Pereira CAC, et al. GnRH analogs X progesterone-lung function evolution in two treatment cohort groups in lymphangioleiomyomatosis (LAM). Am J Respir Crit Care Med 2003; 167: A953.

119 de la Fuente J, Parámo C, Román F, et al. Lymphangioleiomyomatosis: unsuccessful treatment with luteinizing-hormone-releasing hormone analogues. Eur J Med 1993; 2: 377-378.

120 Zahner J, Borchard F, Fischer H, et al. Successful therapy of a post-partum lymphangioleiomyomatosis. Case report and literature review. Schweiz Med Wochenschr 1994; 124: 1626-1632.

121 Harari S, Cassandro R, Chiodini I, et al. Effect of a gonadotrophin-releasing hormone analogue on lung function in lymphangioleiomyomatosis. Chest 2008; 133: 448-454.
122 McCarty KS, Mossler JA, McLelland R, et al. Pulmonary lymphangiomyomatosis responsive to progesterone. $N$ Engl $J$ Med 1980; 303: 1461-1465.

123 Sieker HO, McCarty KS Jr. Lymphangiomyomatosis: a respiratory illness with an endocrinologic therapy. Trans Am Clin Climatol Assoc 1987; 99: 57-67.

124 Johnson SR, Tattersfield AE. Decline in lung function in lymphangioleiomyomatosis: relation to menopause and progesterone treatment. Am J Respir Crit Care Med 1999; 160: 628-633.

125 Taveira-Dasilva AM, Stylianou MP, Hedin CJ, et al. Decline in lung function in patients with lymphangioleiomyomatosis treated with or without progesterone. Chest 2004; 126: 1867-1874.

126 Bissler JJ, McCormack FX, Young LR, et al. Sirolimus for angiomyolipoma in tuberous sclerosis complex or lymphangioleiomyomotosis. N Engl J Med 2008; 358: 140-151.

127 Davies DM, Johnson SR, Tattersfield AE, et al. Sirolimus therapy in tuberous sclerosis or sporadic Lymphangioleiomyomatosis. N Engl J Med 2008; 358: 200-203.

128 Schneider BS, Maimon J, Golub LM, et al. Tetracyclines inhibit intracellular muscle proteolysis in vitro. Biochem Biophys Res Commun 1992; 188: 767-772.

129 Ginns LC, Roberts DH, Mark EJ, et al. Pulmonary capillary hemangiomatosis with atypical endotheliomatosis: successful antiangiogenic therapy with doxycycline. Chest 2003; 124: 2017-2022.

130 Moses MA, Harper J, Folkman J. Doxycycline treatment for lymphangioleiomyomatosis with urinary monitoring for MMPs. N Engl J Med 2006; 354: 2621-2622.

131 El-Hashemite N, Walker V, Kwiatkowski DJ. Estrogen enhances whereas tamoxifen retards development of Tsc mouse liver hemangioma: a tumor related to renal angiomyolipoma and pulmonary lymphangioleiomyomatosis. Cancer Res 2005; 65: 2474-2481.

132 Mendel DB, Laird AD, Smolich BD, et al. Development of SU5416, a selective small molecule inhibitor of VEGF receptor tyrosine kinase activity, as an anti-angiogenesis agent. Anticancer Drug Des 2000; 15: 29-41.

133 Mross K, Drevs J, Muller $\mathrm{M}$, et al. Phase I clinical and pharmacokinetic study of PTK/ZK, a multiple VEGF receptor inhibitor, in patients with liver metastases from solid tumours. Eur J Cancer 2005; 41: 1291-1299.

134 Jones-Bolin S, Zhao H, Hunter K, et al. The effects of the oral, pan-VEGF-R kinase inhibitor CEP-7055 and chemotherapy in orthotopic models of glioblastoma and colon carcinoma in mice. Mol Cancer Ther 2006; 5: 1744-1753.

135 Fritz G, Kaina B. Rho GTPases: promising cellular targets for novel anticancer drugs. Curr Cancer Drug Targets 2006; 6: 1-14.

136 Gau CL, Kato-Stankiewicz J, Jiang C, et al. Farnesyltransferase inhibitors reverse altered growth and distribution of actin filaments in Tsc-deficient cells via inhibition of both rapamycinsensitive and -insensitive pathways. Mol Cancer Ther 2005; 4: 918-926.

137 El-Chemaly S, Taveira-Da Silva A, Stylianou MP, et al. Statins in lymphangioleiomyomatosis: a word of caution. Eur Respir J 2009; 34: 513-520.

138 Nurok M, Eslick I, Carvalho CR, et al. The international LAM registry: a component of an innovative web-based clinician, researcher, and patient-driven rare disease research platform. Limphat Res Biol 2010; 8: 81-87. 